\title{
The Okhotsk-Japan Circulation Pattern and the Heavy Rainfall in Beijing in 2012 Summer
}

\author{
Yafei Wang, ${ }^{1}$ Jianzhao Qin, ${ }^{2}$ and Lijuan $\mathrm{Zhu}^{3}$ \\ ${ }^{1}$ Chinese Academy of Meteorological Sciences, Beijing 100081, China \\ ${ }^{2}$ Meteorological Bureau, Hebei 050011, China \\ ${ }^{3}$ State Key Laboratory of Satellite Ocean Environment Dynamics, Second Institute of Oceanography, State Oceanic Administration, \\ Hangzhou 310012, China
}

Correspondence should be addressed to Yafei Wang; yfwang@cams.cma.gov.cn

Received 12 March 2015; Revised 26 June 2015; Accepted 22 July 2015

Academic Editor: Andrea Montani

Copyright (C) 2015 Yafei Wang et al. This is an open access article distributed under the Creative Commons Attribution License, which permits unrestricted use, distribution, and reproduction in any medium, provided the original work is properly cited.

Using station precipitation and reanalysis data, we examined the evolution of the large-scale circulations associated with the heavy rainfall event that occurred around July 21, 2012 (721 heavy rainfall). This study focuses on a role that the large-scale circulations named "the Okhotsk-Japan (OKJ) circulation pattern" played in causing the heavy rainfall case. We found that the 721 heavy rainfall occurred under a background of the OKJ circulation that persisted for about 10 days. However, the pattern was different from the normal OKJ circulation, for this circulation pattern accompanied a blocking high between the Ural Mountains and the Baikal Lake. This difference resulted from the seasonal change of the basic flow. The related Rossby wave propagated eastward during the persisting period of the dominated OKJ pattern. This caused the development of a low-pressure system around the Baikal Lake and the weakening of a ridge around the Okhotsk Sea. The slow evolution of the OKJ circulation created a favorable environment for the moisture transport to northern China, assisting in the generation of the 721 heavy rainfall.

\section{Introduction}

Beijing area experienced catastrophic flooding caused by unusually heavy rainfall around July 21, 2012 (721 heavy rainfall, see details of the report by Qiu 2012 [1]). The average rainfall in the rain gauges over the whole Beijing region reached $190.3 \mathrm{~mm}$ and the maximum was $225 \mathrm{~mm}$ (Beijing is a big city. There are 16 administrative regions in it. A rain gauge is fixed in every administrative region). The 721 heavy rainfall, one of the several strongest heavy rainfalls over Beijing during the past 61 years, caused a direct economic loss of 1.6 billion and at least 79 people lost their lives. The cause of this concentrated heavy rainfall is an issue worthy of attention not only for meteorological scientific researchers but also for the majority of the Beijing citizens. The city of Beijing, with clear characteristic of East Asian monsoon climate, is located in the plain of northern China west of the Bohai Sea. The period of "late July to early August" is the main rainy season within the summer monsoon [2]. The average location of the subtropical high is conducive to the moisture northward transport, leading to heavy rainfall due to the formation of convergence over northern China $\left(\sim 40^{\circ} \mathrm{N}\right)$. The 721 heavy rainfall was a typical case in North China during the main flooding season. Many studies have investigated the heavy rainfall in North China during the main flooding season, for example, the heavy rainfall study over Hebei (near Beijing) and Beijing area in early August 1963 [3, 4]. The dominant circulation appeared in a wide ridge near the Baikal Lake and a small trough in northern China. Another case was a persistent rainstorm that occurred in North China and the Yellow River during middle July 1958, the cause of which was a narrow north-south shear that resulted from southward shift of positive vorticity. The case studies of the recorded heavy rainfall can greatly improve the physical mechanism understanding of the rainstorm generation, which has common features but also unique points. The above studies of heavy rainfall mostly focused on the local systems and moisture transport conditions, which were not our main concern but they were discussed in Section 5. 
On the other hand, a teleconnection phenomenon named Okhotsk-Japan (OKJ) pattern dominates over Eurasia especially in early summer [5-7]. The maintenance of this pattern is due to the energy dispersion of the Rossby wave that propagates from upstream regions of the Baikal Lake via the Okhotsk Sea to the sea areas east of Japan. The OKJ pattern is favorable for the steady maintenance of Meiyu that is a long lasting rainfall phenomenon around $\sim 30^{\circ} \mathrm{N}$ in China in early summer (see Figure 3 of [6] for the details). Chen and Zhai identified that a double-blocking high type circulation that was likely associated with the OKJ pattern might be responsible for persistent extreme precipitation events in CentralEastern China [8]. However, it is still not clear what is the relationship between OKJ pattern and heavy rainfall. Thus, the researches about the atmospheric circulation with rainstorm occurring need to be strengthened, especially on the response of rainstorm to the teleconnection pattern. In order to understand physical mechanism of the rainfall occurring and provide powerful reference basis for heavy rainfall prediction, a detailed analysis was carried out on the large-scale atmospheric circulation for 721 heavy rainfall, specifically from the perspective of Rossby wave energy propagation in summer.

\section{Data}

The daily precipitation data from 20:00 to the next 20:00 (local time) is provided by the Information Department of the Academy of Meteorological Sciences in July 2012. The daily atmospheric data such as wind, geopotential height, humidity, and pressure are derived from the National Centers for Environmental Prediction/National Center for Atmospheric Research (NCEP/NCAR) global reanalysis dataset with $2.5^{\circ} \times$ $2.5^{\circ}$ spatial resolution and 17 vertical layers from $1000 \mathrm{hPa}$ to $10 \mathrm{hPa}$ [9]. The time period chosen for study is July 2012.

\section{The Relationship between Precipitation and Circulation Evolution}

Figure 1 shows the evolution of the daily precipitation from standard rain gauge of Beijing in July 2012, and its distribution on July 21,2012 . The heavy rain fell mainly during the period from afternoon to before 24:00 on 21 July. However, the daily precipitation was a measurement from 20:00 to next 20:00 (local time). Here the heavy rain days were shown as 2 because the rainfall period crossed the day line 20:00 on July 21. For the coincidence with Chinese media, we still call the case as 721 heavy rainfall, which means the rain mainly fell on July 21 . The rainfall concentrated in the two days when the total rainfall exceeded $160 \mathrm{~mm}$ (Figure 1(a)). The maxima just centered at Beijing over northern China on July 21 (Figure 1(b)). The strong rain belt stretched in a northeast-southwest direction from Beijing to the Sichuan Basin. Figure 2 shows the distribution of daily geopotential height at $500 \mathrm{hPa}(\mathrm{Z} 500)$ from July 16 to 25,2012 respectively. Note that the trough or ridge in middle latitude accompanies relatively colder or warmer air, and the wind blows roughly along the height contour line. For the reason of the brevity, we omitted fields of temperature and wind in Figure 2. S-shaped

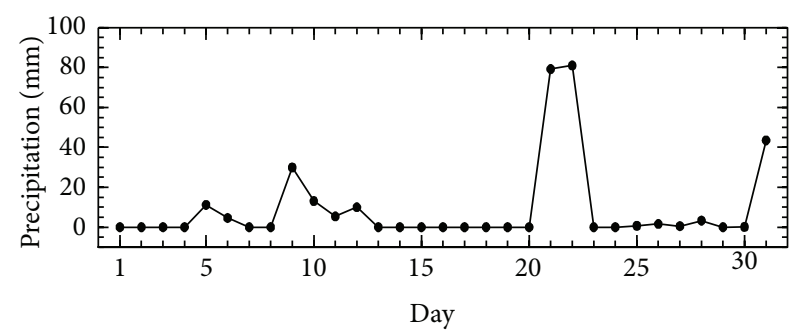

(a)

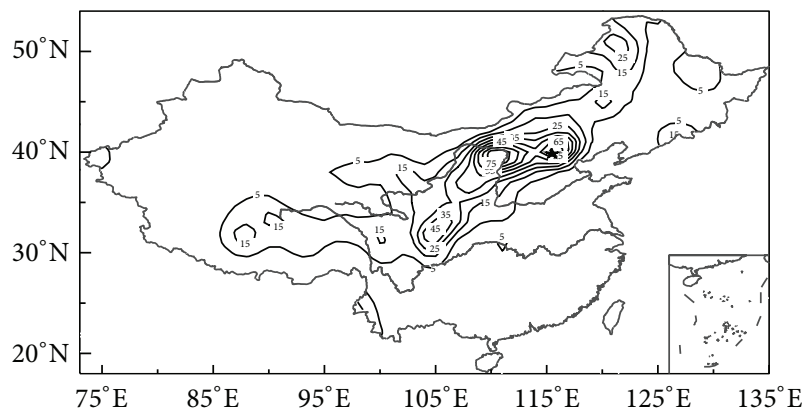

(b)

FIgure 1: (a) Daily precipitation (unit: $\mathrm{mm}$ ) evolution in Beijing (54511) during July 1-31, 2012. (b) The distribution of Chinese precipitation (unit: $\mathrm{mm}$; contour intervals: $10 \mathrm{~mm}$ ) on July 21, 2012. The pentagram is on behalf of Beijing location. The precipitation was accumulated in 24 hours.

westerlies showed a large amplitude in meridional direction since July 16 and one trough and two ridges were located in the areas west of the Baikal Lake $\left(\sim 93^{\circ} \mathrm{E}\right)$, east of the Ural Mountains $\left(\sim 70^{\circ} \mathrm{E}\right)$, and west of the Okhotsk Sea $\left(\sim 120^{\circ} \mathrm{E}\right)$, respectively. The blocking index made by Climate Prediction Center (not shown) shows that the blocking high with warmer air formed east of the Ural Mountains since July 17 and moved eastward to $120^{\circ} \mathrm{E}$ on July 21 . Note that northerly and southerly wind met around Beijing on July 21 (figure omitted). These facts indicated that the middle-high latitude circulation maintained a relatively steady pattern with slight eastward movement. The eastward spread of this circulation pattern made the ridge east of the Okhotsk Sea superimposed on the subtropical high on July 18 and a small trough appeared over the area from Bohai $\left(40^{\circ} \mathrm{N}, 118^{\circ} \mathrm{E}\right)$ to the Yangtze River estuary $\left(30^{\circ} \mathrm{N}, 113^{\circ} \mathrm{E}\right)$. Then, the ridge east of the Okhotsk Sea began to weaken, and the northern China region faced a weak ridge on the east and the trough on the west from July 19 to 21 Note that the ridge over Ural Mountains quickly moved to the north of the Baikal Lake on 22 July, which resulted in the blocking situation in situ even more prominently. The ridge over the Okhotsk Sea disappeared after July 24.

\section{The Energy Dispersion of OKJ Pattern}

The S-shaped wave perturbation pattern of Z500 from July 16 to 25 mentioned above resembled the OKJ pattern. By comparing Figure 2 and Figure 3 of Wang et al. [6], high and low centers showed a similar distribution, especially the ones over the east of the Baikal Lake. The OKJ pattern 


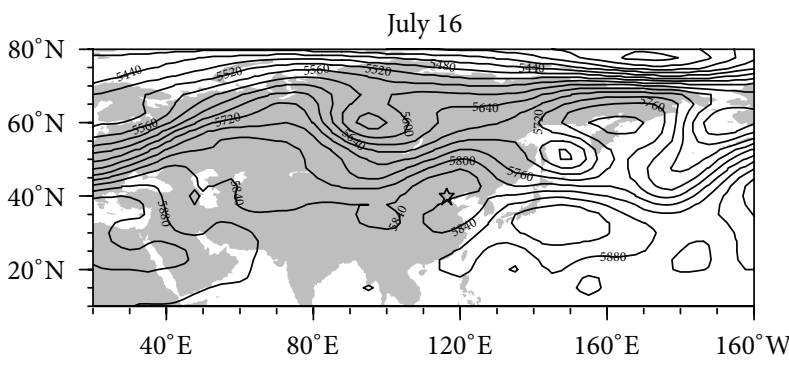

(a)

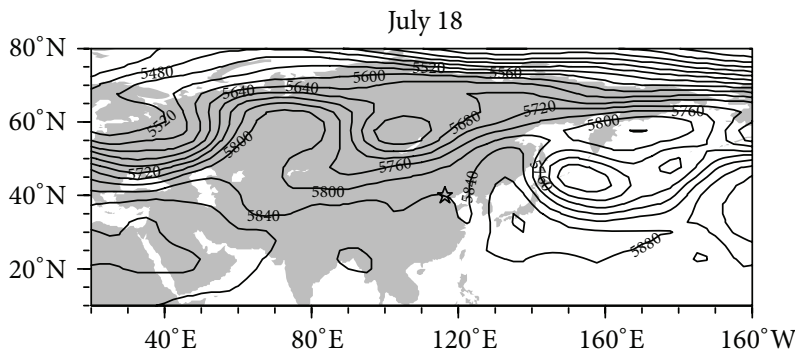

(c)

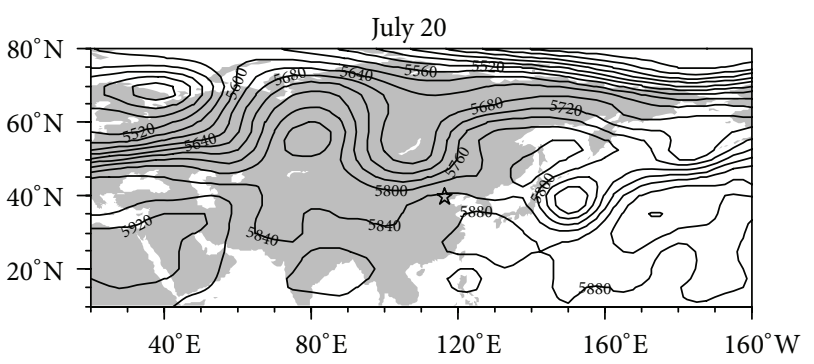

(e)

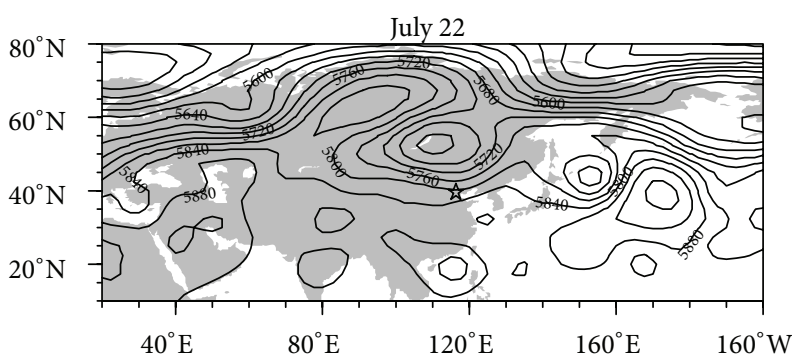

(g)

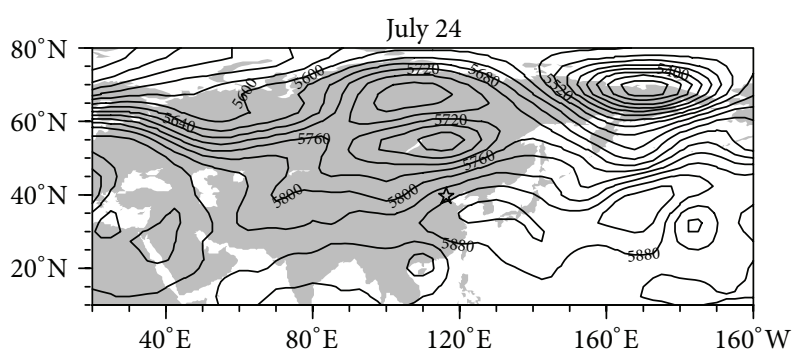

(i)

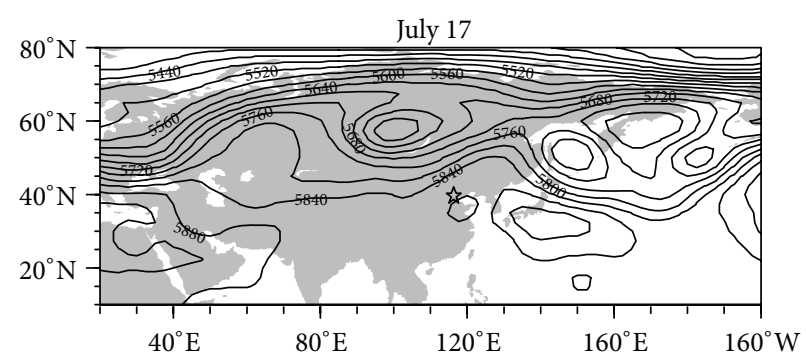

(b)

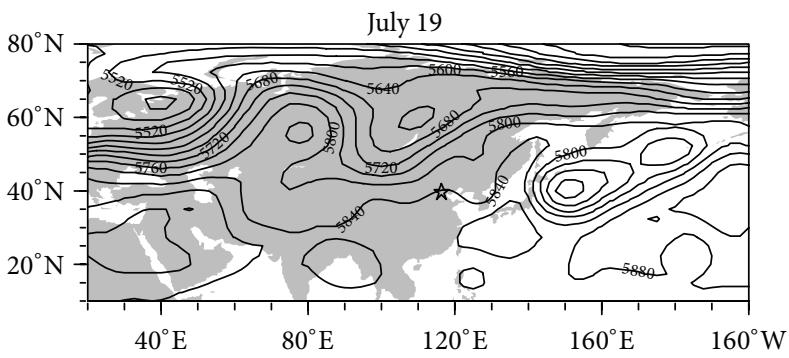

(d)

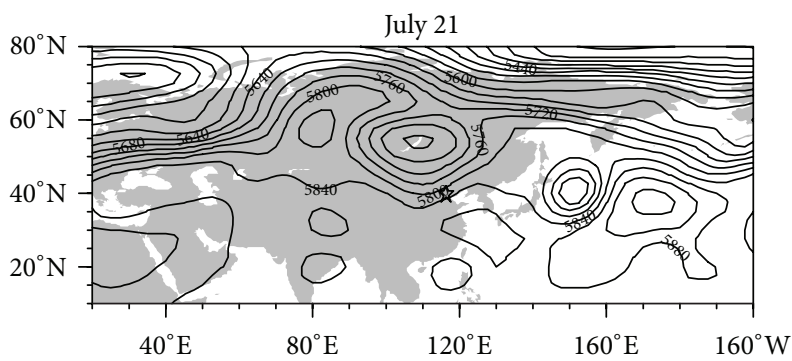

(f)

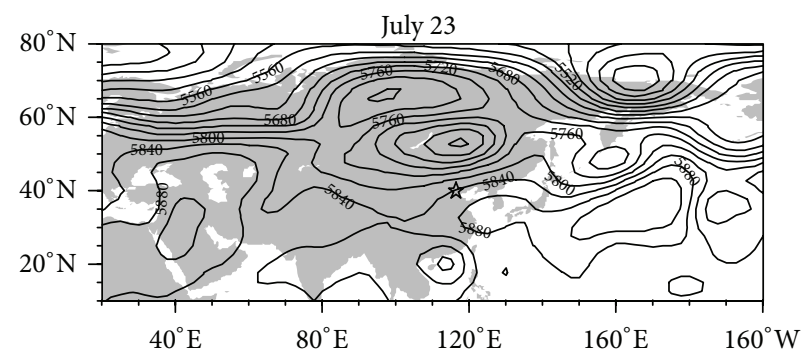

(h)

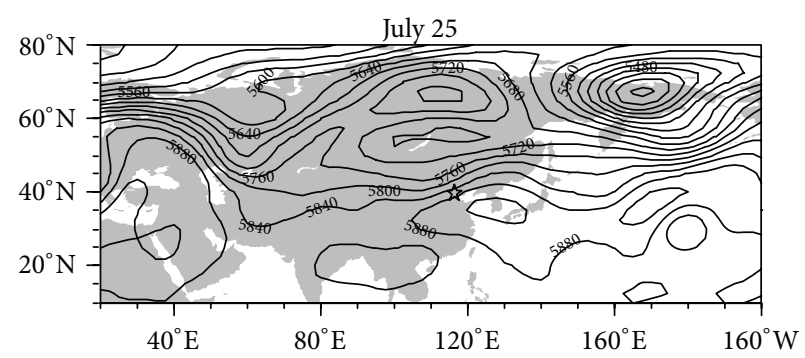

(j)

Figure 2: The daily $500 \mathrm{hPa}$ geopotential height (contour interval: 40 gpm) on July 16-25 (a-j), 2012. The pentagrams are on behalf of Beijing location. 


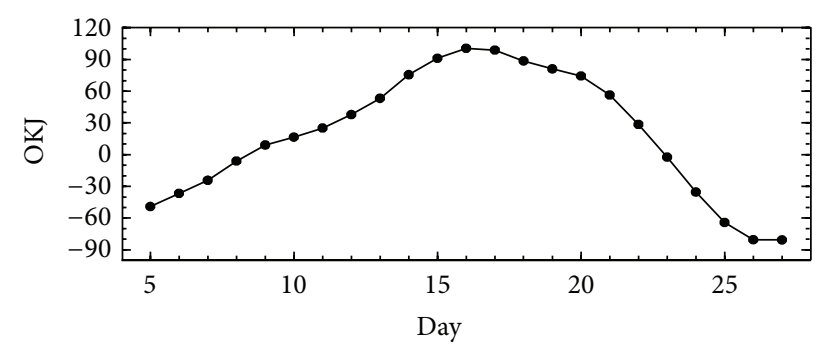

FIGURE 3: Daily OKJ index (nine-day running mean) evolution on July 5-27, 2012. acts as a stationary wave originating from upstream regions of the Caspian Sea via the Okhotsk Sea to the sea areas east of Japan. The OKJ wave, usually occurring in June, could help to keep a stable flow pattern over East Asia especially by strengthening the ridge over the Okhotsk Sea and Meiyu front. The probability that the OKJ pattern occurs in midsummer is relatively low [5,7]. The typical OKJ pattern with positive phase has two ridges and two troughs locating near the Ural Mountains, the Okhotsk Sea, the Baikal Lake, and sea areas east of Japan, respectively, which can also be found in Figure 2. An index designed by Wang et al. [10] to describe the typical OKJ pattern is as follows:

$$
\mathrm{OKJI}=\frac{100 \times\left[Z^{*}\left(57.5^{\circ} \mathrm{N}, 137.5^{\circ} \mathrm{E}\right)-Z^{*}\left(57.5^{\circ} \mathrm{N}, 92.5^{\circ} \mathrm{E}\right) / 2-Z^{*}\left(40^{\circ} \mathrm{N}, 160^{\circ} \mathrm{E}\right) / 2\right]}{2} .
$$

$Z^{*}$ expressed the normalized Z500 anomalies, which were calculated by dividing the climatological anomalies by the standard deviation. A positive index is indicative of anomalously high height around the Okhotsk Sea and low heights around the Lake Baikal and the sea region east of Japan. We assigned the first grid point $\left(57.5^{\circ} \mathrm{N}, 137.5^{\circ} \mathrm{E}\right)$ as twice the weight of the other two grid points to make the sum of the weight equal to zero as suggested by Wallace and Gutzler [11]. Figure 3 shows the evolution of the 9-day running mean OKJ index in July. The index presented a changing curve with arched shape, which was beyond 30 from July 12 to 22 . This suggested a significant OKJ pattern. The index value was above 60 from July 14 to 21 , and above 100 on July 16 . The OKJI higher than 30 persisted about 10 days. Note that the OKJ index just reflects the average intensity for the action centers around the three grid points in (1). The actual locations of the action centers would be slightly deviate from the three grid points. In addition, the heavy rain occurred 5 days later when the OKJ index reached the highest value, which implies that the OKJ pattern only provides a large-scale situation that is favorable to produce heavy rain. We could not fix the time of the occurrence of the heavy rain only by the strong signal of the index. Here we investigated the role of the stationary wave since the circulation pattern kept steady. Figure 4 shows the distribution of Z500 and its wave activity flux from July 17 to 27 . In order to better identify the stationary wave in synoptic scale, we applied 9-day running mean centered at the marked dates in each picture. The horizontal wave activity flux (HWAF) is the calculation of the formula provided by Plumb [12], and Wang and Yasunari [13] gave the details. The HWAF represents the stationary propagation's magnitude and direction of wave energy in the two dimensions. The energy of stationary wave spreading in a group velocity is usually much faster than the averaged wind speed. The propagation could strengthen every quasi-stationary circulation systems downstream. The bold arc roughly depicts the energy propagation along the OKJ pattern track in Figure 4 . There were two ridges and one trough located at east of Ural Mountains $\left(\sim 75^{\circ} \mathrm{E}\right)$, at the Okhotsk Sea $\left(\sim 140^{\circ} \mathrm{E}\right)$, and near the Baikal Lake $\left(\sim 105^{\circ} \mathrm{E}\right)$, respectively since July 17 . The ridge east of the Ural Mountains developed into a blocking high on July 21 and then strengthened with slightly eastward moving. Strong wave activity flux propagated in two routes before July 21: one wave from upstream regions of Ural Mountains to Baikal Lake and the other one from the Okhotsk Sea to the sea areas east of Japan. The HWAF was broken at the area east of the Baikal Lake, which implies that wave energy piled up near the upstream regions of Ural Mountains and resulted in the development of blocking high. The two beams of the fluxes were connected at the broken area due to the propagations strengthening upstream from July 21 to 22 . The wave energy quickly dispersed to the downstream regions. The connection between the wave energy propagation and the case of strong precipitation is under study.

\section{Water Vapor Transport}

The water vapor transport volume is crucial for precipitation occurring, especially for the heavy rainfall. A rainstorm would not occur unless there is functionally strong convergence of water vapor transport. The 721 heavy rainfall was just the example. Figure 5 shows the water vapor flux and its convergence field. The large convergence center kept staying southwest of the Tibet Plateau. Thin and scattered water vapor convergence centers occurred in South China from July 15 to 19 . A small range of water vapor convergence center with maximum value began to appear in northern China, including Beijing on July 20 . The water vapor convergence suddenly increased to peak on July 21 when the heavy rain dropped, which could induce the latent heat release by convection. This is because a cyclonic rotation in the front of trough near Beijing can generate a wide range of convective activity. Large water vapor convergence center occurred again in North China on July 24 and then moved northeastward. The water vapor source in North China was mostly from the South China Sea, which was the water vapor transport by the southerly from the subtropical high. 


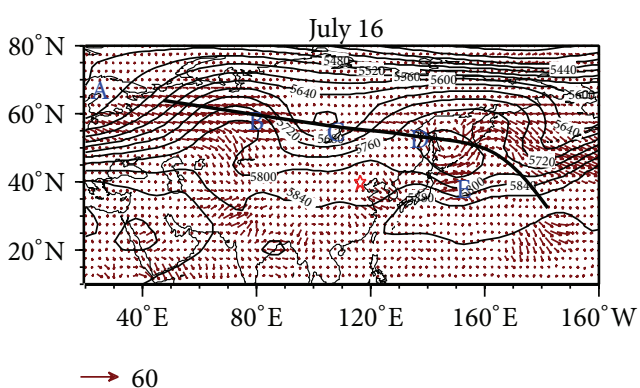

(a)

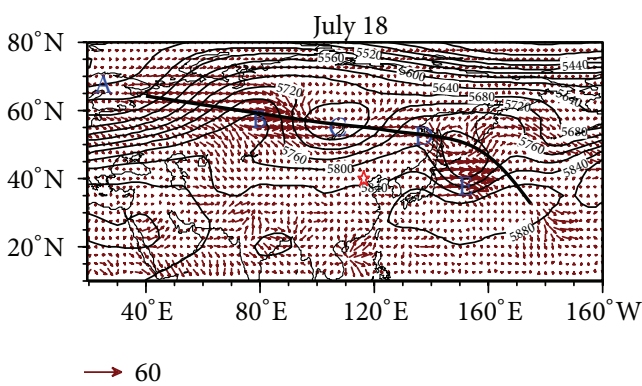

(c)

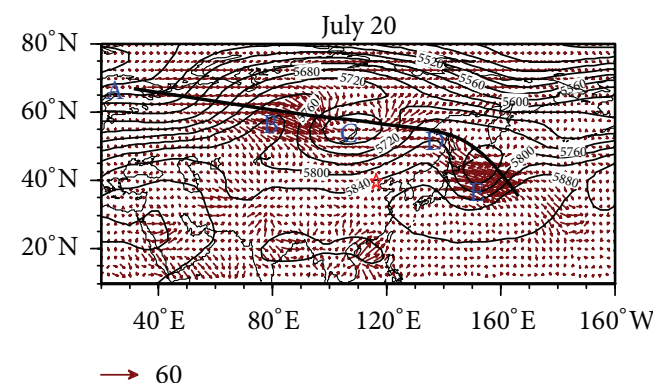

(e)

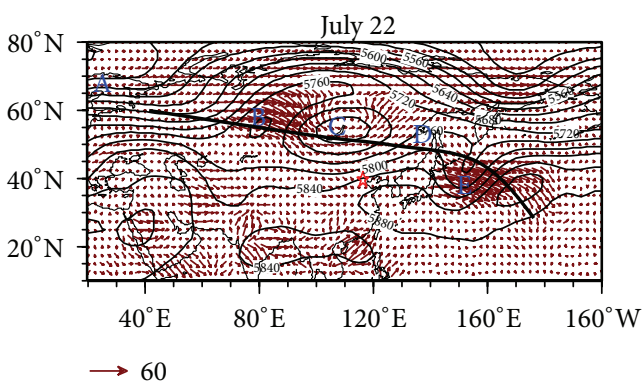

(g)

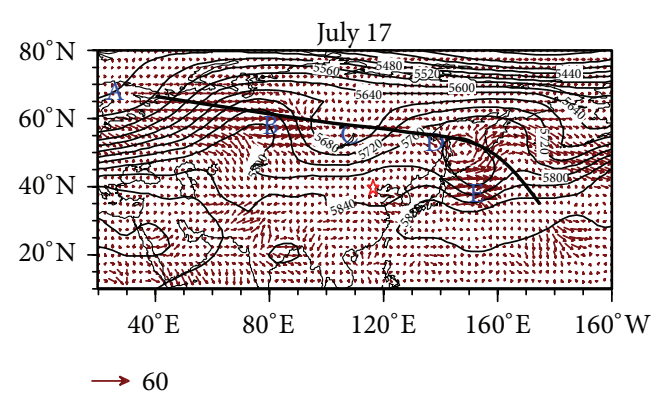

(b)

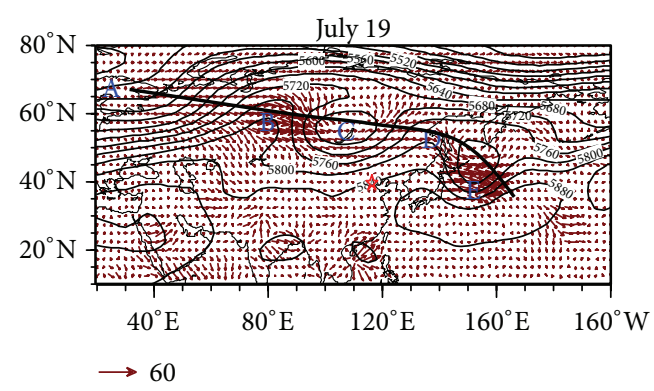

(d)

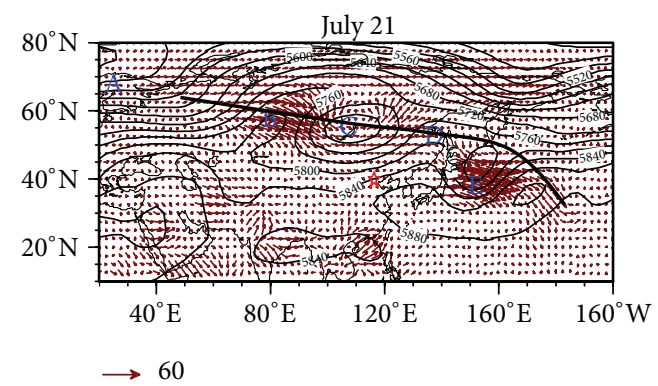

(f)

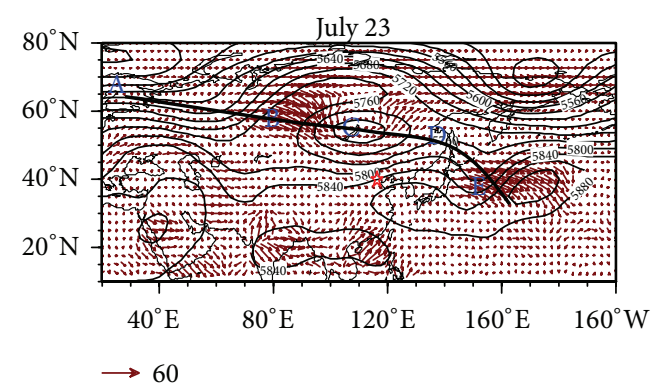

(h)

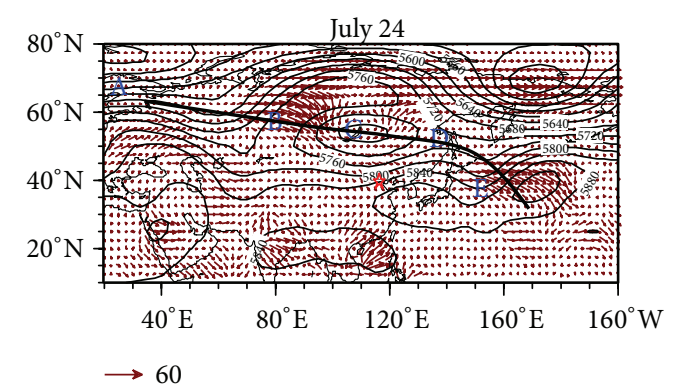

(i)

FIGURE 4: $500 \mathrm{hPa}$ geopotential height (contour, interval: $40 \mathrm{gpm}$ ) and HWAF fields (vector, unit: $\mathrm{m}^{2} \mathrm{~s}^{-2}$ ) on July 17-25 (a-i), 2012. The thick arch line is the OKJ track, that is, the route of strong wave activity flux from higher latitudes to southern China. The red pentagrams are on behalf of Beijing location. 
July 15

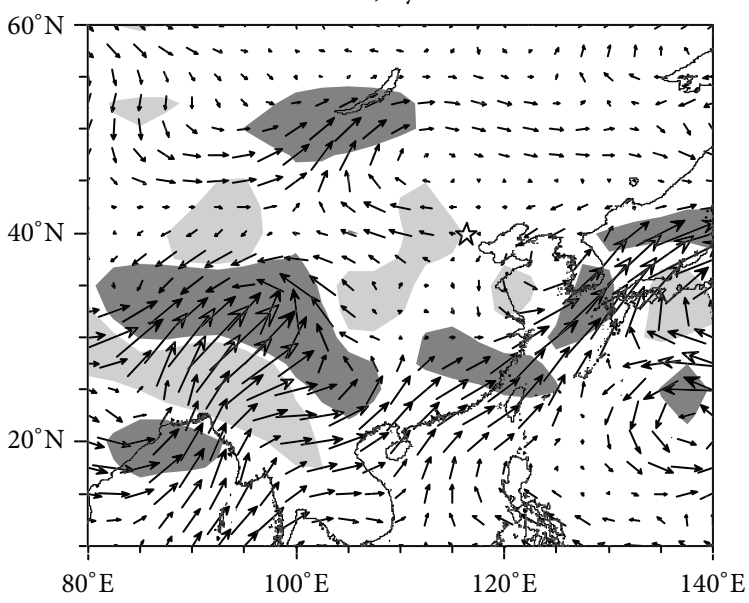

$\longrightarrow 30$

(a)

July 17

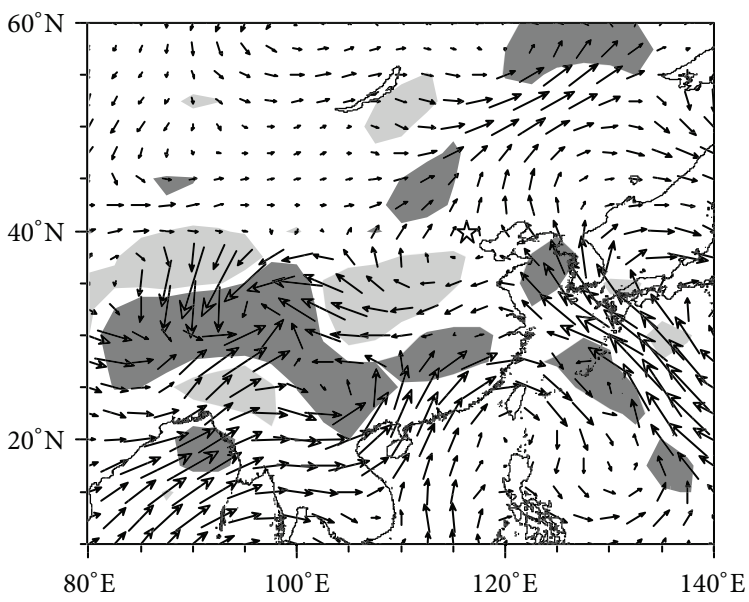

$\longrightarrow 30$

(c)

July 19

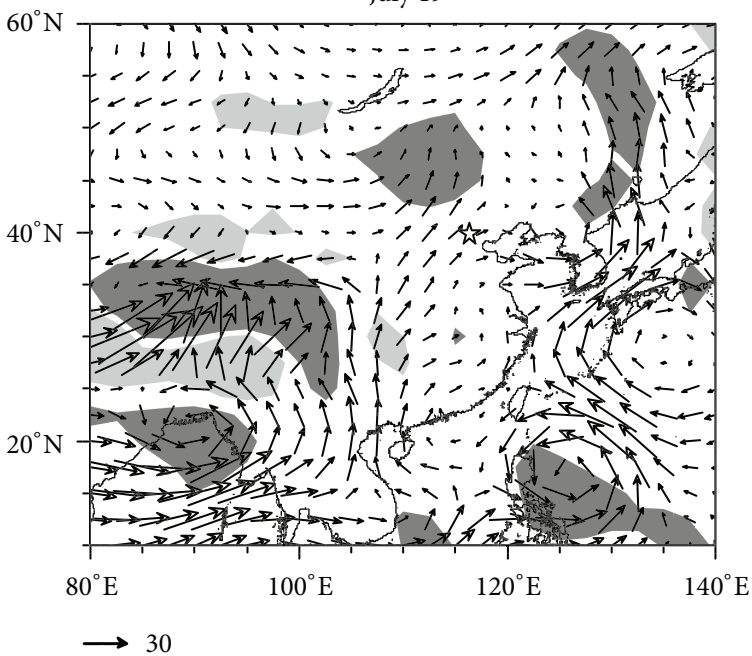

(e)

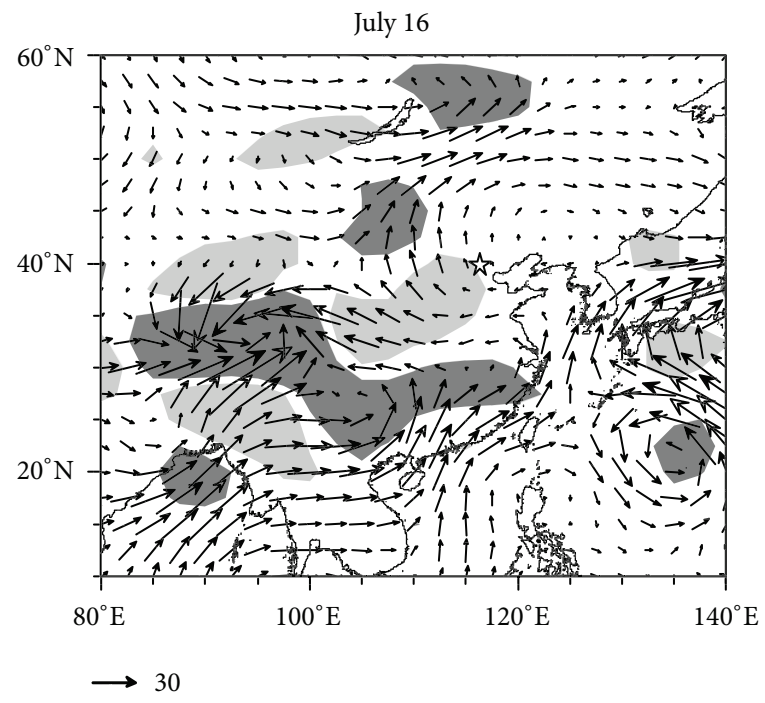

(b)

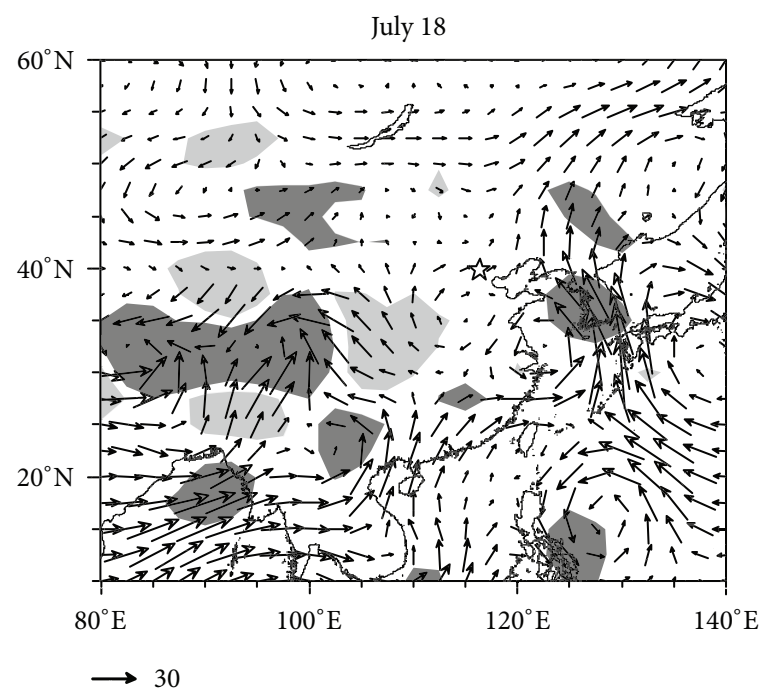

(d)

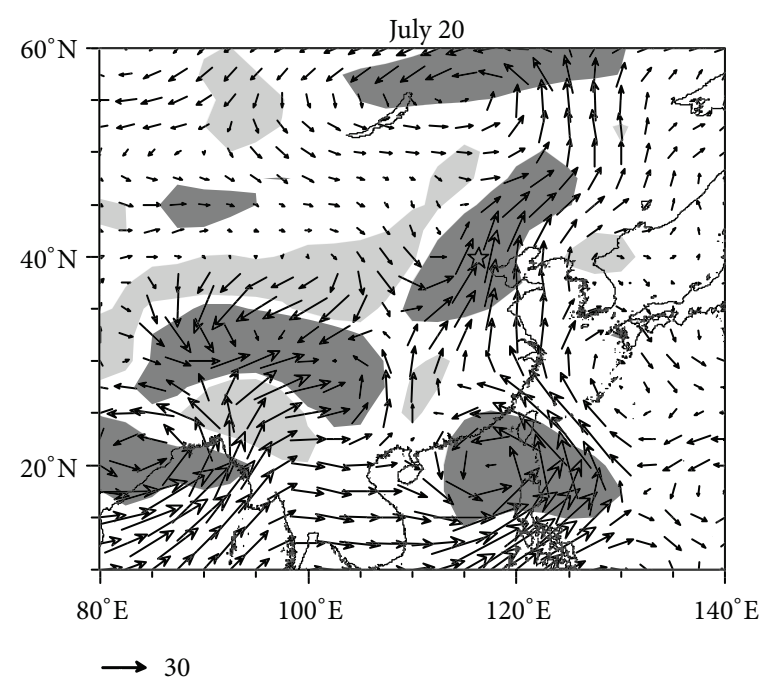

(f)

Figure 5: Continued. 


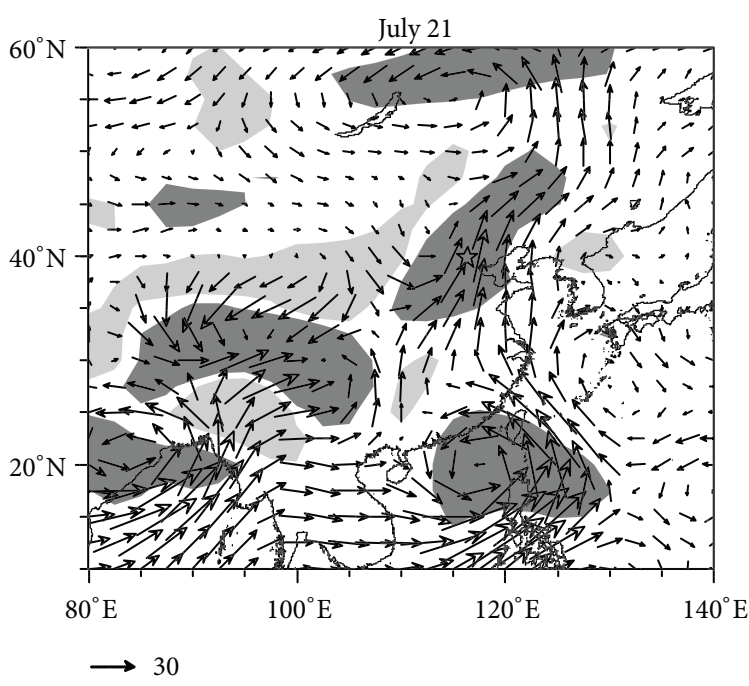

(g)

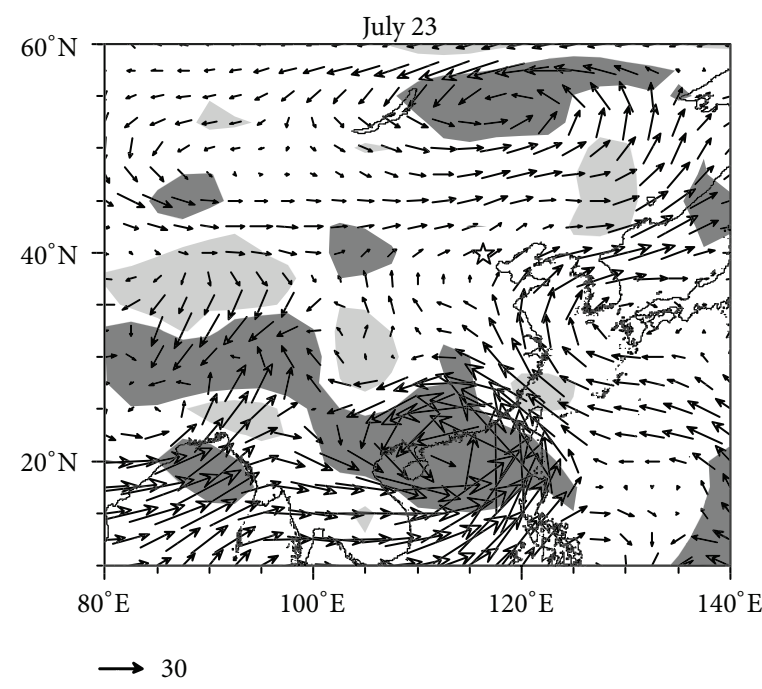

(i)

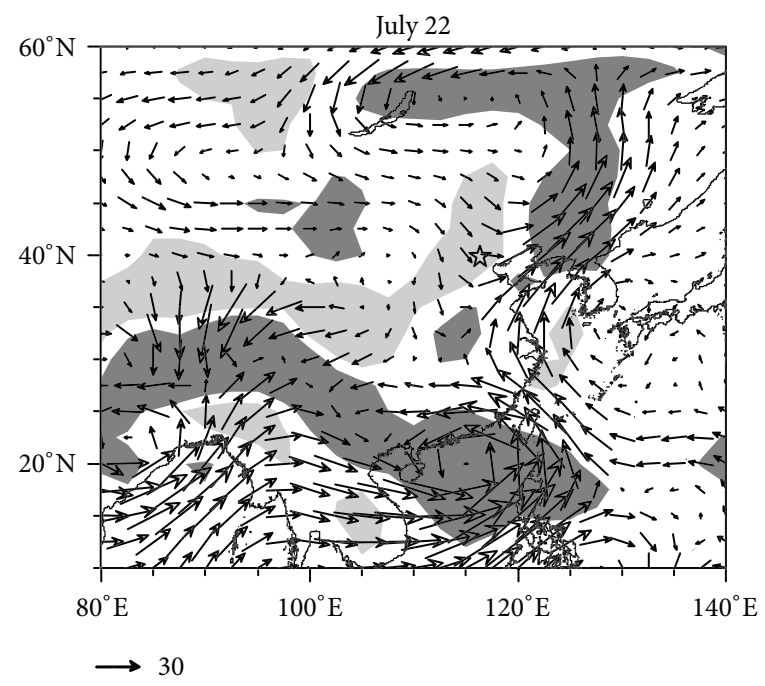

(h)

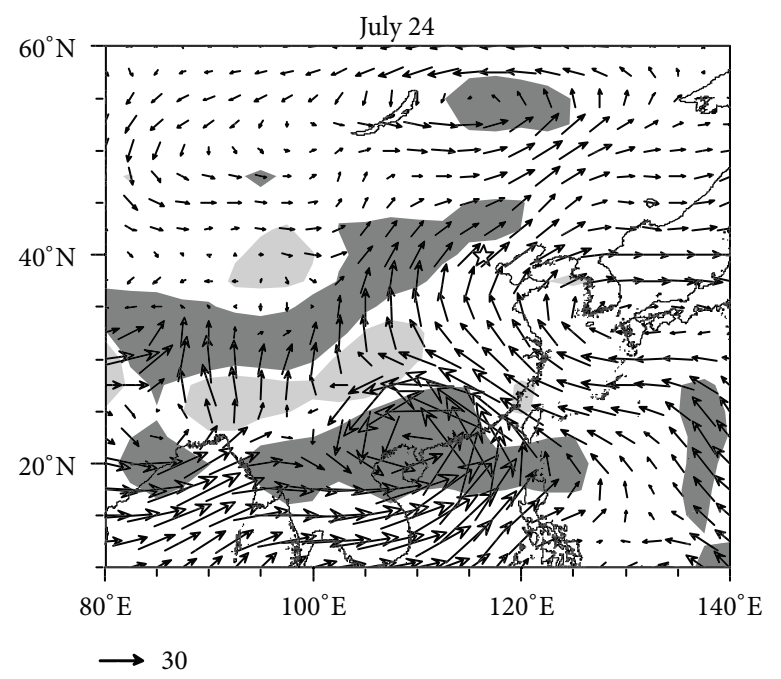

(j)

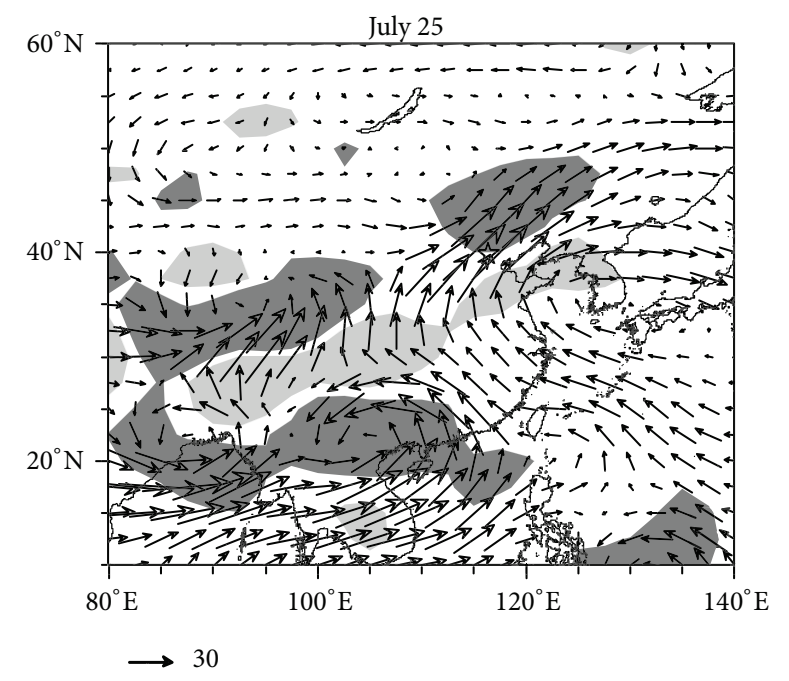

(k)

FIGURE 5: $1000 \mathrm{hpa}-100 \mathrm{hpa}$ vapor flux (vector, unit: $\mathrm{kg} /(\mathrm{s} * \mathrm{~m})$ ) and water vapor flux divergence (shade: dark color (light color) on behalf of convergence (divergence) where divergence $<-2 \mathrm{~kg} /\left(\mathrm{m}^{2} * \mathrm{~s}\right)\left(>2 \mathrm{~kg} /\left(\mathrm{m}^{2} * \mathrm{~s}\right)\right)$ ) for July $15-25(\mathrm{a}-\mathrm{k}), 2012$. The pentagrams are on behalf of Beijing location. 


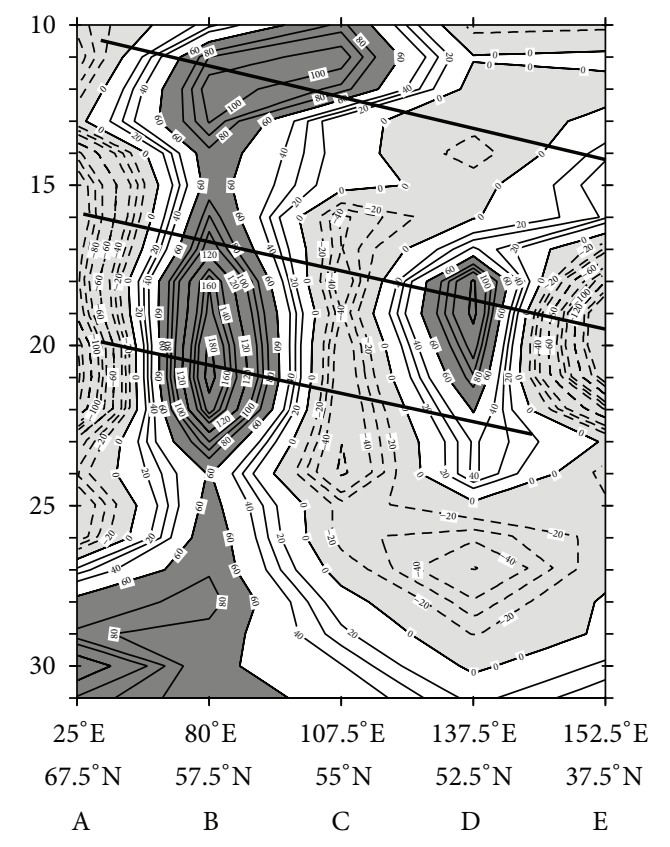

(a)

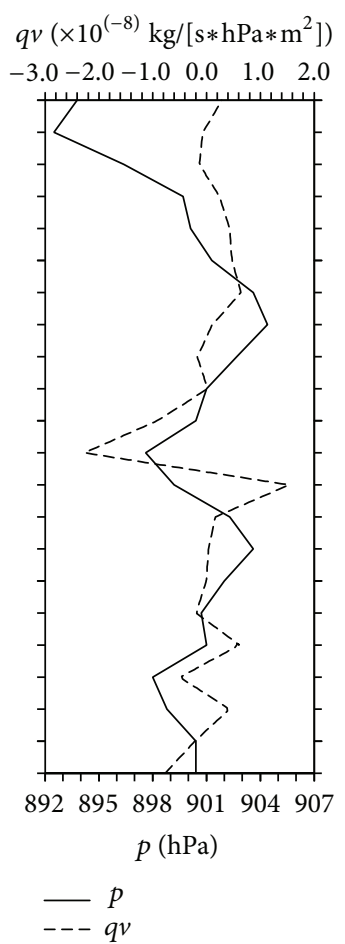

(b)

FIGURE 6: The time evolution of daily $500 \mathrm{hPa}$ geopotential height deviations (contour interval: $10 \mathrm{gpm}$ ) along A-F (Figure 4) (a) and surface pressure (solid line, unit: $\mathrm{hPa}$ ) and $850 \mathrm{hPa}$ water vapor flux divergence (dashed line, unit: $\mathrm{kg} /\left(\mathrm{s} * \mathrm{hPa} * \mathrm{~m}^{2}\right)$ ) in Beijing (b) from July 10 to 31, 2012.

In order to link the circulation in high latitude with water vapor transport in North China, we calculated the time evolution of daily Z500 deviation, surface pressure, and $850 \mathrm{hPa}$ water vapor flux divergence in Beijing along the bold arc line in Figure 4 as shown in Figure 6. The OKJ track was indicative of the bold arc line connecting height anomaly centers. The height deviation centers of ",,+-+ " in high latitudes kept staying around the points "A, B, and C," especially from July 15 to 23 , which indicated that the circulation in high latitudes was relatively stable. There were mainly three OKJlike propagations along the line connecting the action centers as shown in Figure 6(a). The wave energy of upstream region reached point A on July 11 and reached point E on July 14 in the first spread. The wave energy travelled directly from upstream area of point A to E from July 16 to 19 in the second spread. The third spread from July 20 to 22 with relatively short distance. Note that the height amplitude at $\mathrm{C}$ during July 18-20 was smaller, which coincides with the flux broken area in Figure 4. There were strong positive height anomalies around point B near the Ural Mountains where a blocking high was dominating during this period. On the other hand, the pressure in Beijing reached minimum value on July 21 with the strongest water vapor convergence as shown in Figure 6(b). Interestingly, the pressure variation trend in Beijing coincided well with the negative Z500 anomalies at point $\mathrm{C}$, which suggests that the OKJ propagation generated a delayed impact on the circulation over Beijing.
In order to examine if the convective instability is crucial for the heavy rainfall, we calculated many elements including the equivalent potential temperature in troposphere and the convective available potential energy (figures omitted). Unfortunately, we cannot find any result that can be explained explicitly. The convective instability around Beijing existed indeed. However, the strongest signals appeared neither around Beijing nor in the heavy rain period.

\section{Discussions and Summaries}

The above results suggested that the 721 heavy rainfall was occurring under the background of OKJ-like circulation that continually generated wave energy propagation in middlehigh latitudes. The OKJ rarely occurs in July, especially in late July, which is different from the normal OKJ wave presence in June. The OKJ pattern in July corresponded well with a blocking high over the Ural Mountains instead of that over the Okhotsk Sea in June. With the eastward wave energy dispersion, the ridge between the Okhotsk Sea and Baikal Lake stayed stable, but with less intensity than that of the normal pattern. Since a wide trough stably stretched from Baikal Lake to Xinjiang province in China, the flow in the front of the trough gradually dominated over northern China where the southwesterly with warmer air from lower latitude met the westerly with colder air in the middle latitude. As atmosphere in East Asian summer tends to behave quasi-barotropic, 
upper and lower air roughly blew in the same direction in North China, which suggests the water vapor convergence in a quite deep layer. Thus, the gradually evolving circulation was favorable for the rainstorm over North China. Note that 721 rainstorm is a rarely particular case involving OKJ pattern. The OKJ pattern here was a necessary condition rather than sufficient condition to the heavy rainfall occurrence. The slow evolution of large-scale circulation may produce the possibility of heavy rain occurring in any place of northern China, not limited to Beijing. We would like to emphasize that this stable circulation indeed provided a favorable situation for inducing the heavy rainfall in North China. The OKJ pattern lasts for about 9 days whereas the rainstorm only lasts for about 16 hours when the OKJ pattern decayed. A large amount of Rossby wave energy dispersed to downstream areas due to the adjustment of the circulation over the Ural Mountains for developing the blocking high. This dispersion might result in strengthening of the low over the Baikal Lake and weakening of the ridge over the Okhotsk Sea (Figure 4). The circulation systems evolved eastward slowly with the quasi-stationary wave propagation in the OKJ pattern, which would help to suddenly release the energy in a local place where the energy piled up largely. The rainstorm might be the reflection of instantaneous energy release. Figure 6(a) shows that three significant wave energy beams spread from upstream region of point A to points D-E during the period of July 11-24. The heavy rainfall related to the negative height anomaly at point $\mathrm{C}$ strengthened just during the period when the wave energy beams strongly spread. This phenomenon implies that a forecaster may begin to consider a sudden weather change happening when the energy has piled up due to the first OKJ wave propagation from upstream area of Ural Mountains. However, we cannot determine the exact time and place of such sudden change that was mainly due to a combined effect of the evolution speed of circulation, terrain influence, water vapor transport, and so forth. The 721 rainstorm was just the case with all the conditions to achieve the best allocation. Thus, the rainstorm may take place on some day within one week in North China in late July so long as the OKJ wave energy dispersed to point C. Comprehensive information is needed to predict when and where the rainstorm will occur. Note that there is not an explicit connection between heavy precipitation case and the blocking index or the OKJ index.

The OKJ pattern rarely occurs in July whereas it frequently takes place in June accompanying the Okhotsk High. In late July, the land-sea thermal difference around the Okhotsk Sea decreases and summer monsoon shifts northward from the Yangtze River to North China. Consequently, the Okhotsk High is hard to develop in July. In other words, the formation of the blocking high over the Okhotsk Sea can lead to the concentrated precipitation in the Yangtze and Huaihe Rivers Basin but not in North China [5]. The seasonal change of the basic flow caused this difference. The blocking high firstly developed around the Ural Mountains in this case. The eastward spread of energy strengthened the S-shaped perturbation of westerly circulation at downstream area. Thus, a weak ridge formed over the Okhotsk Sea, which led to positioning of the North China area between the trough on the west and the ridge on the east. This situation benefited the precipitation over this area. The S-shaped perturbation is the reflection of OKJ propagation in the positive phase [10]. Note that there was an active typhoon named Kanu in late July, which moved along the peripheral line of the subtropical high. The cyclone arrived at the East China Sea on July 17 and moved northward to landfall at Jeju island on July 18. The cyclone made landfall at North Korea on July 19 and downgraded to tropical depression, which moved out of the South Korea on July 21. To some extent, the typhoon activity at Korean Peninsula played a role in preventing rapid eastward spread of midhigh latitudes systems. Regardless, heavy rainfall is not caused by a single factor, that is, the evolution of the large-scale circulation. The synergistic effects by other factors including terrain conditions at Beijing area and instability development of mesoscale systems were also important, which are all needed for further research.

The results are as follows: (1) The 721 heavy rainfall occurred under a background of the OKJ circulation that persisted for about 10 days; (2) this circulation was characterized by a blocking high between the Ural Mountains and the Baikal Lake, which was different from the normal OKJ circulation due to the seasonal change of the basic flow. The eastward Rossby wave propagation was broken around the Baikal Lake and regenerated on July 20, leading to the development of a low pressure system around the Baikal Lake and the weakening of a ridge around the Okhotsk Sea; and (3) the OKJ circulation slowly moved eastward and created a favorable environment for the moisture transport to northern China, assisting in the generation of the 721 heavy rainfall.

\section{Conflict of Interests}

The authors declare that there is no conflict of interests regarding the publication of this paper.

\section{Acknowledgments}

This study was supported by the National Natural Science Foundation of China (nos. 41375091 and 41575055) and the Project of the Ministry of Science and Technology of China (no. 2012CB417202).

\section{References}

[1] J. Qiu, "Urbanization contributed to Beijing storms," Nature, 2012.

[2] M. Yoshino, Rainfall, Frontal Zones and Jet Streams in Early Summer over East Asia, vol. 3 of Bonner Meteorologische Abhandlungen, Meteorologisches Institut der Universität, 1963.

[3] S. Y. Tao, Storm in China, China Science Press, 1980 (Chinese).

[4] Y. H. Ding, Monsoons over China, Kluwer Academic Publishers, 1994.

[5] Y. Wang, "Effects of blocking anticyclones in Eurasia in the rainy season (Meiyu/Baiu season)," Journal of the Meteorological Society of Japan, vol. 70, no. 5, pp. 929-951, 1992.

[6] Y. Wang, K. Yamazaki, and Y. Fujiyoshi, "The interaction between two separate propagations of Rossby waves," Monthly Weather Review, vol. 135, no. 10, pp. 3521-3540, 2007. 
[7] H. Nakamura and T. Fukamachi, "Evolution and dynamics of summer time blocking over the Far East and the associated surface Okhotsk high," Quarterly Journal of the Royal Meteorological Society, vol. 130, no. 599, pp. 1213-1233, 2004.

[8] Y. Chen and P. Zhai, "Two types of typical circulation pattern for persistent extreme precipitation in Central-Eastern China," Quarterly Journal of the Royal Meteorological Society, vol. 140, no. 682, pp. 1467-1478, 2014.

[9] E. Kalnay, M. Kanamitsu, R. Kistler et al., “The NCEP/NCAR 40-year reanalysis project," Bulletin of the American Meteorological Society, vol. 77, no. 3, pp. 437-471, 1996.

[10] Y. Wang, P. Zhai, and J. Qin, "Construction of the OKJ teleconnection index," Theoretical and Applied Climatology, vol. 114, no. 1-2, pp. 303-314, 2013.

[11] J. M. Wallace and D. S. Gutzler, "Teleconnections in the geopotential height field during the Northern Hemisphere winter," Monthly Weather Review, vol. 109, no. 4, pp. 784-812, 1981.

[12] R. A. Plumb, "On the three-dimensional propagation of stationary waves," Journal of the Atmospheric Sciences, vol. 42, no. 3, pp. 217-229, 1985.

[13] Y. Wang and T. Yasunari, "A diagnostic analysis of the wave train propagating from high-latitudes to low-latitudes in early summer," Journal of the Meteorological Society of Japan, vol. 72, no. 2, pp. 269-279, 1994. 

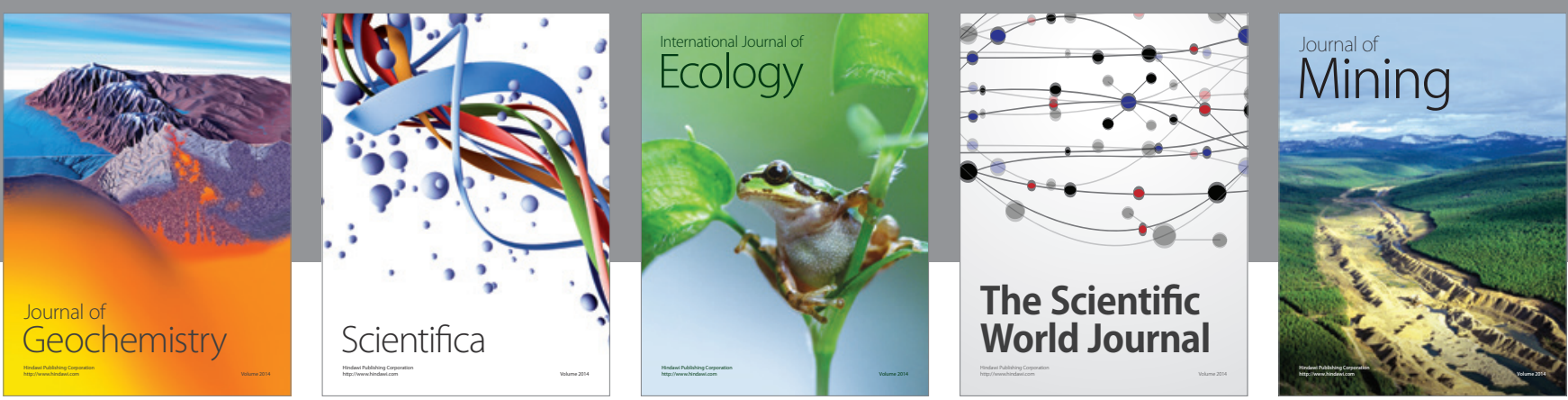

The Scientific World Journal
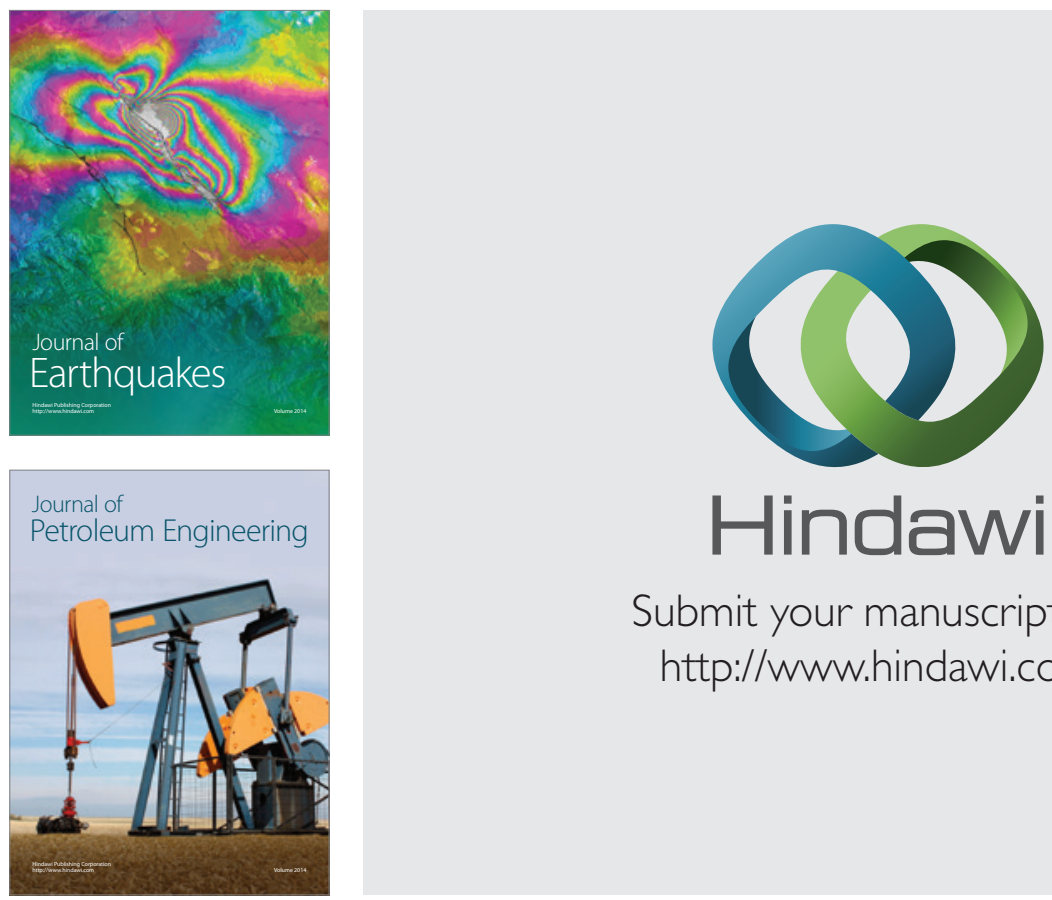

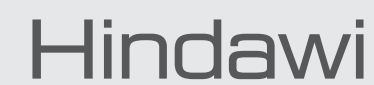

Submit your manuscripts at

http://www.hindawi.com
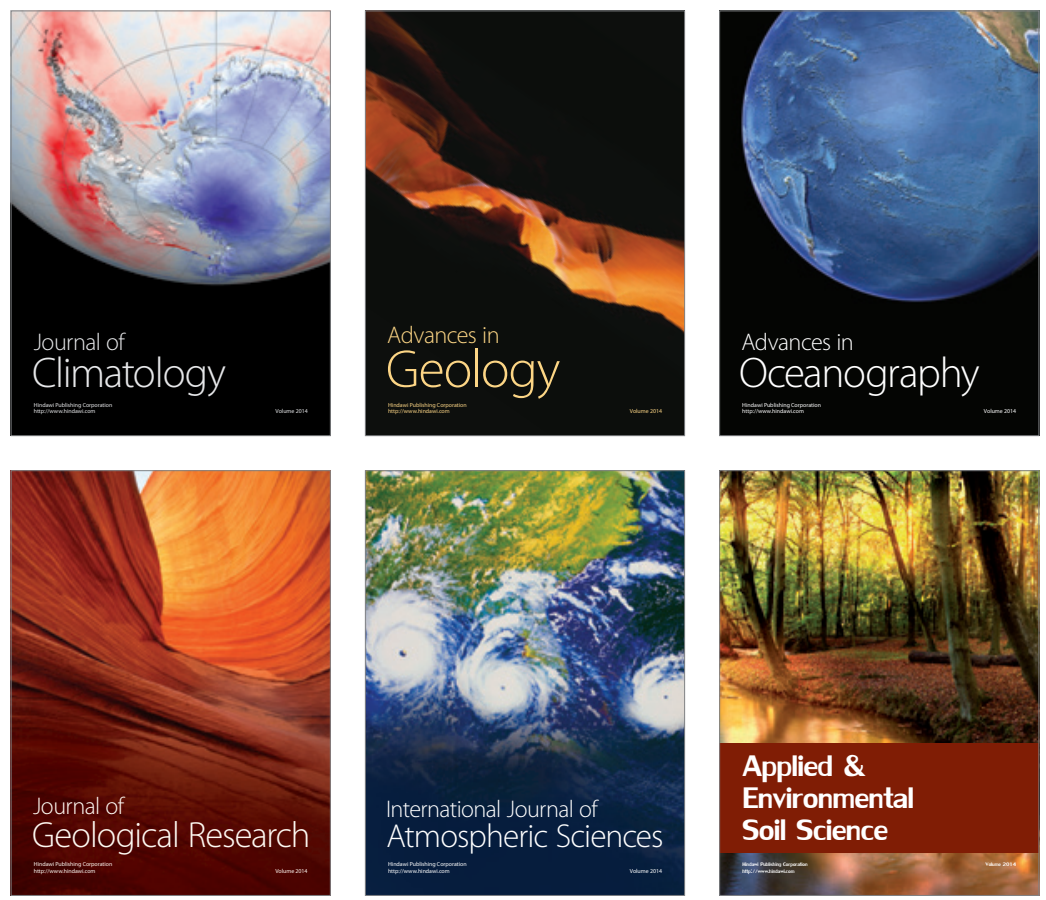
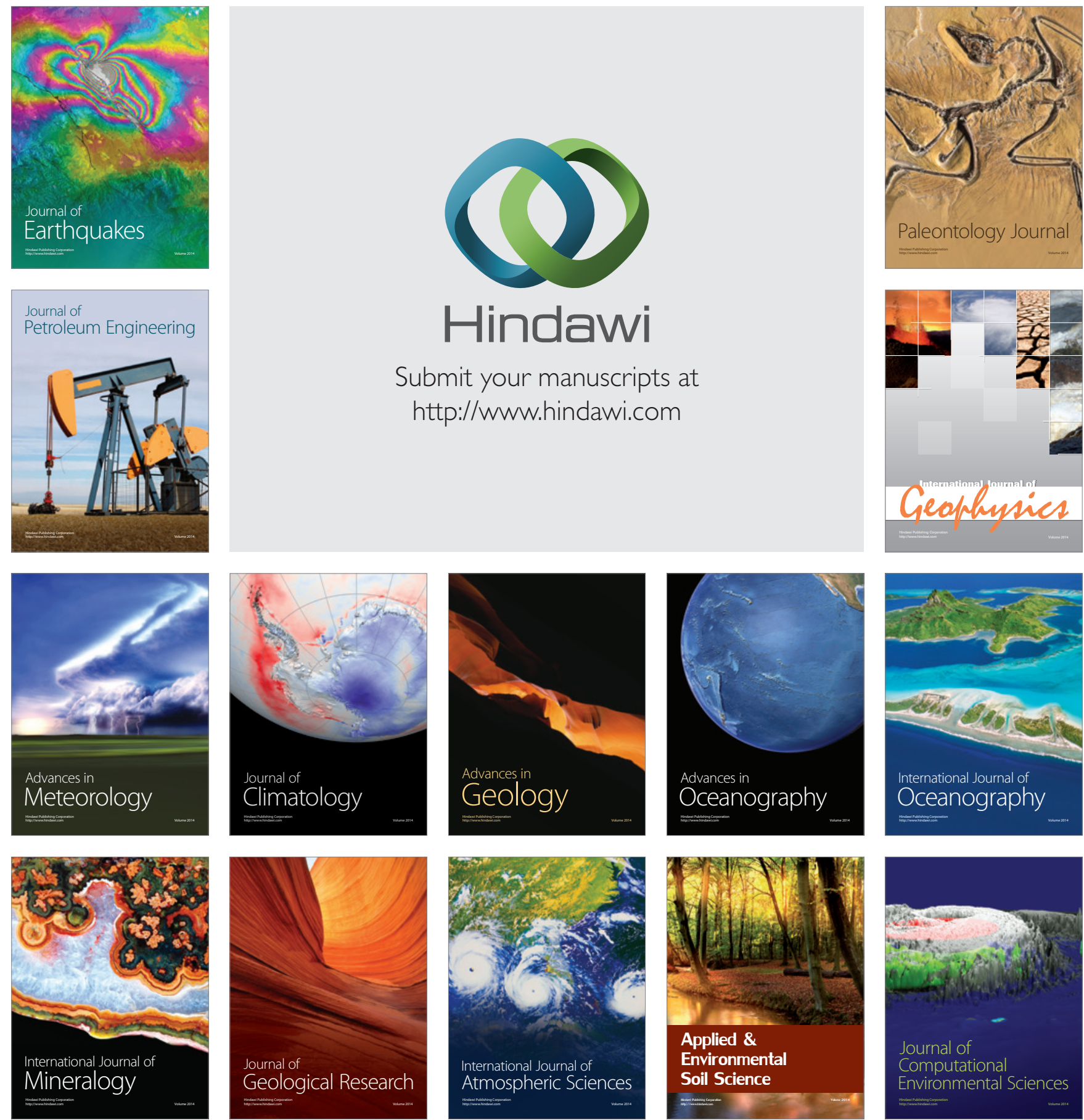